\title{
Endurance performance in masters athletes
}

\author{
Peter Reaburn • Ben Dascombe
}

Received: 9 December 2007 / Accepted: 3 January 2008 / Published online: 24 January 2008

(C) (EGREPA) 2008

\begin{abstract}
Masters athletes are typically older than 35 years of age and systematically train for, and compete in, organized forms of sport specifically designed for older adults. They are motivated to participate in masters sport for a wide variety of reasons. Age-related declines in endurance performance are observed across the endurance sports of running, orienteering, rowing, and swimming. These declines are curvilinear from age 35 years until approximately age 60-70 years and exponential thereafter. The decline in endurance performance appears primarily due to an age-related decrease in $\mathrm{VO}_{2 \max }$ secondary to an age-related decrease in $\mathrm{HR}_{\max }$ and possible age-related declines in stroke volume and arteriovenous oxygen difference. While performance velocity at lactate threshold decreases with age in masters endurance athletes, it appears to increase relative to $\mathrm{VO}_{2 \max }$ while exercise economy is maintained. There also appears an age-related decrease in active muscle mass, type II muscle fiber size, and blood volume that contribute to decreased endurance performance. However, research suggests that maintenance of training intensity and volume into older age may mediate the rate of age-related decline in $\mathrm{VO}_{2 \max }$, stroke volume, arteriovenous oxygen difference, blood volume, and muscle mass in masters endurance athletes.
\end{abstract}

Keywords Endurance $\cdot$ Ageing $\cdot$ Performance

\section{P. Reaburn $(\square)$}

Department of Health and Human Performance,

Central Queensland University,

Rockhampton QLD, 4701, Australia

e-mail: p.reaburn@cqu.edu.au

B. Dascombe

Athlete and Coach Services, Western Australian Institute of Sport, Perth, Australia

e-mail: bdascombe@wais.org.au

\section{Introduction}

Masters athletes are individuals who systematically train for, and compete in, organized forms of competitive sport specifically designed for older adults. These aging individuals present a unique model to study the effects of high levels of physical training into older age [94].

Each sport's national or international governing body determines the age to define a masters athlete. In general, the age is determined by the age at which the world record in open elite sport peaks. While masters athletes are typically older than 35 years of age, masters' competition in swimming begins at age 25 years, track and field at 35 years, and golf at 50 years. For the purpose of this paper, masters athletes are defined as participants over the age of 35 years who are either highly conditioned and experienced competitive athletes who have completed their formal competitive careers, the 'weekend warriors' who sporadically train and compete, or older competitors who have resumed physical training after long periods of physical inactivity [62].

Masters athletes participate in organized competitive sport for a number of reasons. Previous research from masters swimming [46, 97], athletes competing at multisport events [67, 84], or older people involved in regular exercise and sport [59] has shown that masters athletes participate for enjoyment, competition, physical fitness, health benefits, social, travel, stress relief, personal challenge, and skill development reasons. However, the factors of enjoyment, health and fitness benefits, social, and competition appear the primary drivers for involvement [84, 97].

While masters athletes participate for a variety of reasons, differences in motivation have been observed across age, gender, and years of involvement in masters 
sport [46, 97]. Across both genders, there is an age-related decrease in motivation to participate in masters sport [84]. Males appear more achievement-oriented and females more focused on the health, social, and enjoyment benefits [46, 59]. Finally, it appears that athletes with five or more years of involvement rate social motives as more important than less experienced athletes [97].

For the purposes of this paper, both the model for endurance performance proposed by Coyle [24] and factors affecting aerobic performance previously identified by empirical research on masters athletes will be discussed. Coyle [24] proposed that performance velocity in endurance events is dependent upon a number of physiological factors (Fig. 1) including:

- maximal $\mathrm{O}_{2}$ consumption $\left(\mathrm{VO}_{2 \max }\right)$

- maximal heart rate

- stroke volume

- lactate threshold

- economy of movement

- muscle fiber type, morphology and capillarization

- aerobic enzyme activity

Apart from these above factors, previous research suggests that both muscle mass [47, 73] and blood volume $[23,25,89]$ may affect endurance performance in masters athletes. Thus, within this review, each of the above factors will be discussed, including:

1. Declines in endurance performance observed in masters sports;

2. Age-related changes in $\mathrm{VO}_{2 \max }$, lactate threshold and economy in masters endurance athletes;

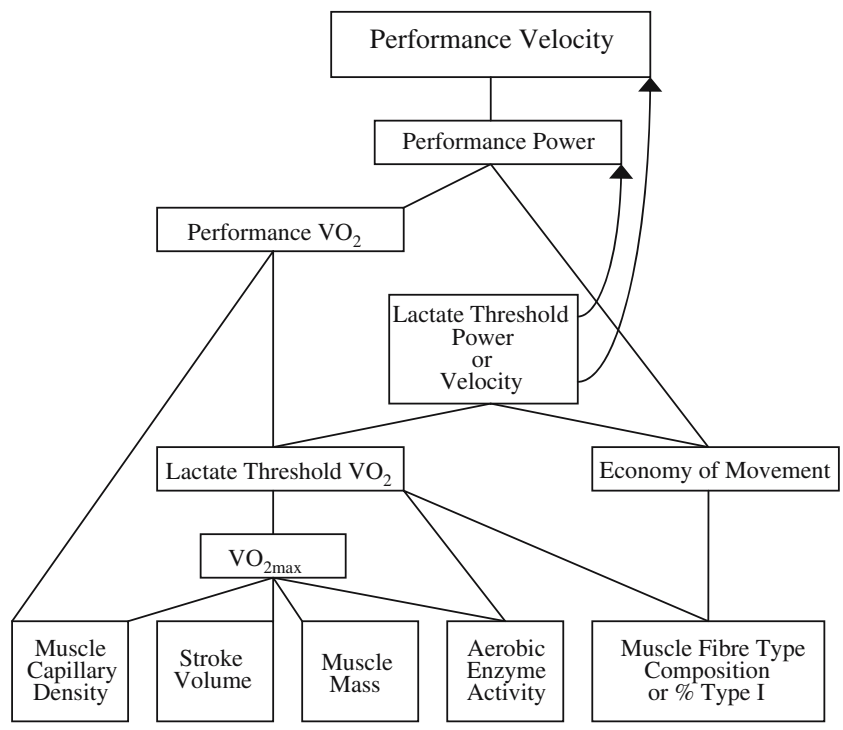

Fig. 1 Model of the physiological factors that determine endurance performance in masters endurance athletes (adapted from [24])
3. Central (maximum heart rate; maximum stroke volume; blood volume) factors contributing to age-related declines in endurance performance in masters athletes;

4. Peripheral factors (muscle mass; muscle fiber composition, size, and capillarization; muscle enzyme activity) contributing to age-related declines in endurance performance in masters athletes.

\section{Declines in endurance performance}

Age-related declines in endurance performance have been observed in marathon and road running $[8,28,51,92,99$, 107], track endurance running [5, 35, 65, 90, 109], orienteering [7], indoor rowing [83], and long distance swimming $[9,27,30,45,75,93]$.

The age-related decrease in endurance performance of elite level masters endurance athletes appears curvilinear from age 35 years until approximately age 60-70 years and exponential thereafter. Specifically, endurance performance appears (Figs. 2 and 3) maintained until approximately 35 years of age, followed by modest decreases until 50 years of age, with a progressive decrease in performance thereafter with the greatest declines occurring after the age of 70 years in endurance running events $[5,94]$ and after age $70-80$ years in $1,500 \mathrm{~m}[27,30,93]$ or 1 -h swimming events [9].

A cross-sectional study of swimming performance from the U.S. Masters Swimming Championships observed a greater rate of decline in swim performance in females than males across all swim events from 50 to $1,500 \mathrm{~m}$ [93]. In endurance running events, the decrease in performance is greater in women compared to men, possibly due to either biological or sociological differences [94]. These authors suggested that these gender differences may partly be explained by selection bias. That is, there are a smaller number of female runners in the older age groups. This

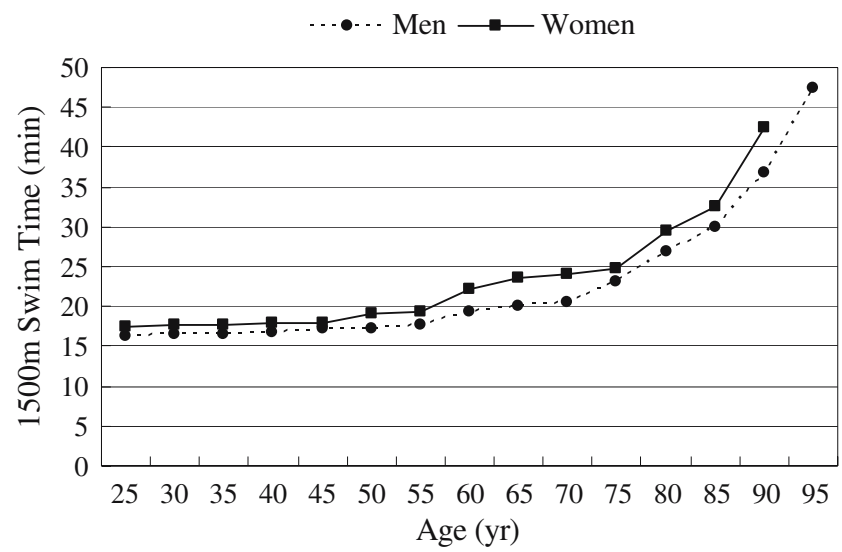

Fig. 2 World-records for the 1,500 $\mathrm{m}$ swimming event in men and women with respect to age (adapted from Tanaka and Seals [94]) 


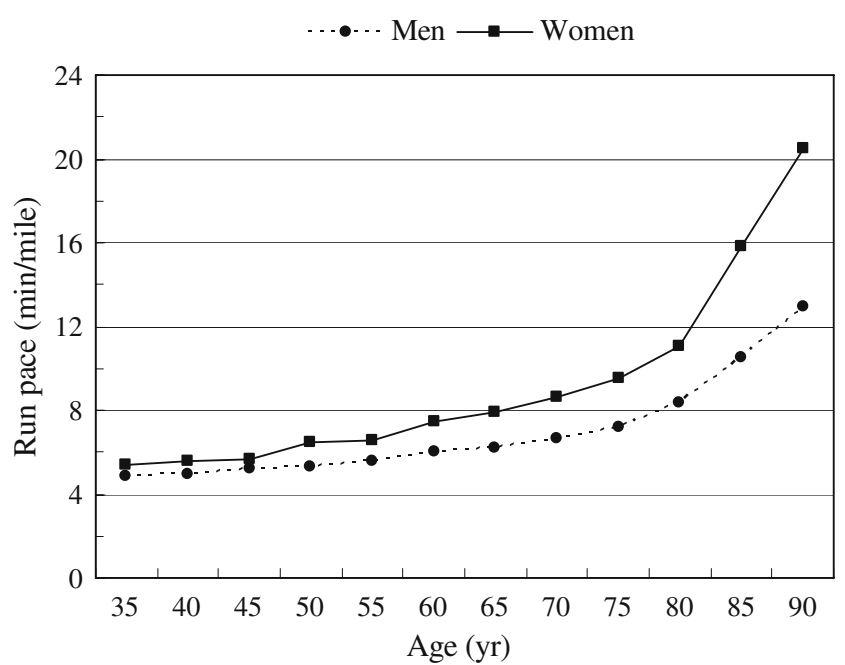

Fig. 3 Running speed with relation to age for the marathon worldrecords [99]

suggestion was supported by recent research examining the running times, age, and gender of 415,000 run performances in the New York Marathon between 1983 and 1999 [51]. They observed that female marathon participation showed a significantly greater percentage increase in all age groups compared to the males and that the finishing times for the top 50 male and female finishers over the past two decades showed significantly greater improvement in the masters' age groups than the younger age groups, especially in the older female athletes [51].

The above age-related declines in endurance performance have been suggested to be due to decreased training volumes and intensities as a result of increased work and family commitments [87, 88, 103], behavioral factors such as reduced motivation to train $[64,94]$, few masters athletes having coaches [87], and masters athletes spending less overall time in training than international caliber younger athletes, even though the percentage time spent in the various types of training appears similar [87, 103]. Apart from these sociopsychological factors, previous research has shown that age-related reductions in $\mathrm{VO}_{2 \max }$, and changes in lactate threshold and economy in masters athletes may also affect endurance performance.

\section{Maximal aerobic power}

Coyle [24] has identified that maximal aerobic power $\left(\mathrm{VO}_{2 \max }\right)$ is a major contributor to endurance performance. In both young [66] and older [28, 96] endurance athletes, $\mathrm{VO}_{2 \max }$ is a strong predictor of running performance with stronger correlations observed between endurance performance and $\mathrm{VO}_{2 \max }$ in populations heterogenous for $\mathrm{VO}_{2 \max }$ $[52,94]$.
$\mathrm{VO}_{2 \max }$ is estimated to decline approximately $10 \%$ per decade after the age of 25 years in healthy sedentary aging individuals [15]. An age-related reduction in $\mathrm{VO}_{2 \max }$ has also been well documented in both cross-sectional and longitudinal studies of male and female endurance athletes undertaking high levels of endurance training into older age [11, 32, 40, 42, 48, 53, 56, 57, 71, 72, 78, 106, 108], suggesting that some decrease in $\mathrm{VO}_{2 \max }$ appears inevitable with aging, despite physical training into older age. However, the rates of decline in $\mathrm{VO}_{2 \max }$ have been reported to be reduced [54, 55, 78], similar [108], or greater [47, 71] than age-matched sedentary individuals.

Earlier studies suggested the rate of decline in $\mathrm{VO}_{2 \max }$ of masters endurance athletes to be only half that observed in sedentary aging individuals [40, 48, 53]. In a classic longitudinal study, Kasch and others [53] measured $\mathrm{VO}_{2 \max }$ in 12 physically active men aged 44-79 years $10,15,20$, and 25 years of follow-up after an initial investigation. The $\mathrm{VO}_{2 \max }$ of the group was $60 \%$ greater than those reported for sedentary men of similar age [15]. The decline in $\mathrm{VO}_{2 \max }$ was $13 \%$ (5\% per decade) over the 25 -year period. The rate of decline per annum of $0.24 \mathrm{mLkg}^{-1} \mathrm{~min}^{-1}$ was half of the $0.45 \mathrm{mLkg}^{-1} \mathrm{~min}^{-1}$ reported for sedentary aging men [15]. However, more recent studies have suggested accelerated decline in $\mathrm{VO}_{2 \max }$ in older endurance athletes as a result of decreased training volumes and intensities (32, 71 ) or the examined athletes possessing higher than normal initial $\mathrm{VO}_{2 \max }$ values at baseline (94).

Gender differences in the rate of age-related decline in $\mathrm{VO}_{2 \max }$ are commonly observed in masters endurance athletes [11, 104]. For example, Brown et al. [11] recently reported declines of 0.65 and $0.39 \mathrm{mLkg}^{-1} \mathrm{~min}^{-1}$ year $^{-1}$ in male (17-64 years) and female (16-54 years) high performance cyclists, respectively. Fitzgerald et al. [32] used meta-analysis to suggest that $\mathrm{VO}_{2 \max }$ in aging females declines at different rates in sedentary $\left(0.35 \mathrm{mLkg}^{-1} \mathrm{~min}^{-1}\right.$ year $\left.{ }^{-1}\right)$, active $\left(0.44 \mathrm{mLkg}^{-1} \mathrm{~min}^{-1}\right.$ year $\left.^{-1}\right)$, and endurancetrained $\left(0.62 \mathrm{mLkg}^{-1} \mathrm{~min}^{-1} \mathrm{year}^{-1}\right)$ subjects. Wilson and Tanaka [106] also used meta-analysis to suggest age-related declines in $\mathrm{VO}_{2 \max }$ of $0.40,0.39$, and $0.46 \mathrm{mLkg}^{-1} \mathrm{~min}^{-1}$ year $^{-1}$ in sedentary $(n=6,231)$, active $(n=5,261)$, and endurance-trained $(n=1,961)$ males. Hawkins et al. [47] reported a longitudinal study of 86 male $(53.9 \pm 1.1$ year) and 49 female $(49 \pm 1.2$ year) masters endurance runners tested 8.5 years after initial measures of $\mathrm{VO}_{2 \max }$. Their findings suggested that $\mathrm{VO}_{2 \max }$ declines in male and female masters athletes at a rate similar to or greater than that expected in sedentary older adults. Soon after, Pimental et al. [71] observed that $\mathrm{VO}_{2 \max }$ declined by $0.54 \mathrm{mLkg}^{-1} \mathrm{~min}^{-1}$ year $^{-1}$ in 89 endurance-trained men aged 21-74 years compared to a decline of $0.39 \mathrm{~mL} \mathrm{~kg}{ }^{-1} \cdot \mathrm{min}^{-1} \cdot$ year $^{-1}$ in 64 sedentary men aged 20-75 years. However, when stratifying for age, the endurance-trained subjects $\mathrm{VO}_{2 \max }$ 
declined by $0.2 \mathrm{mLkg}^{-1} \mathrm{~min}^{-1}$ year $^{-1}$ between $20-50$ years, increasing to $0.89 \mathrm{mLkg}^{-1} \mathrm{~min}^{-1}$ year $^{-1}$ between ages 50 and 74 years.

These differences in rates of decline in $\mathrm{VO}_{2 \max }$ may be explained by the decreases in training volume, frequency, and intensity commonly observed in masters endurance athletes $[42,61,71,100,106,108]$. These changes in training habits have been shown to influence the rate of decline in $\mathrm{VO}_{2 \max }$ in both male and female masters endurance athletes $[56,71,72,94,101]$. In their classic longitudinal study, Trappe et al. [101] initially examined 53 highly trained and competitive distance runners. Twentytwo years later, these men were classified as highly trained $(n=10)$, fitness trained $(n=18)$, untrained $(n=15)$, and fit older $(n=10)$, depending on their continued level of training and age. All groups experienced a significant decrease in $\mathrm{VO}_{2 \max }$ that was related to the amount of training between evaluations. The reductions were $6,10,15$, and $15 \%$ lower per decade for the highly trained, fitness trained, untrained, and fit older, respectively. Similarly, Katzel et al. [56] compared longitudinal changes in $\mathrm{VO}_{2 \max }$ in 41 male endurance runners who, after initial testing 4-13 years prior, were divided into "high training" $(n=7)$, "moderate training" ( $n=21)$, and "low training" $(n=13)$ groups, depending on their training regimes and exhibited agerelated declines in $\mathrm{VO}_{2 \max }$ of 2.6, 4.6, and $4.7 \%$, respectively. Taken together, these results suggest that high-intensity training and maintenance of training volume may mediate the age-related declines in $\mathrm{VO}_{2 \max }$ and endurance performance. This would suggest that high intensity and high volume training is important in maintaining or attenuating age-related decreases in $\mathrm{VO}_{2 \max }$ and endurance performance, a suggestion strongly supported by research focused on maximizing endurance performance in younger athletes [14].

In summary, in both male and female masters endurance athletes, there is an age-related decrease in $\mathrm{VO}_{2 \max }$ that contributes to decreased endurance performance. However, the decline in $\mathrm{VO}_{2 \max }$ is dependent on the degree to which the athletes maintain training volume and intensity, the age of the subjects, or the heterogeneity of the group(s) studied.

According to the modified Fick equation, $\mathrm{VO}_{2 \max }$ is the product of both maximal heart rate and maximal stroke volume (central factors), and maximal arteriovenous oxygen difference (peripheral factors [4]). Arteriovenous oxygen difference is further influenced by a variety of factors including muscle mass, the capacity of the blood to transport and relinquish oxygen (blood volume, hemoglobin), and the capacity of the working tissues to take up and utilize oxygen (capillarization, muscle fiber type, aerobic enzyme activity). To fully understand the age-related declines in $\mathrm{VO}_{2 \max }$, an examination of each of these factors in masters endurance athletes is warranted.

\section{Central factors affecting maximal aerobic power}

Maximum heart rate

An age-related decrease in maximum heart rate $\left(\mathrm{HR}_{\max }\right)$ is commonly observed in male and female endurance athletes [11, 32, 34, 42, 47, 48, 71, 94, 95, 106]. For example, Pimental et al. [71] observed a highly significant $(p<$ 0.0001 ) in inverse relationship between age and $\mathrm{HR}_{\max }$ in 80 male endurance runners between the ages of 21 and 74 years. Tanaka et al. [95] used both meta-analysis (351 studies, $n=18,712)$ and laboratory-based maximal treadmill testing $(n=514)$ to establish $\mathrm{HR}_{\max }$ in male and female healthy sedentary, active, and endurance-trained (vigorous endurance exercise greater than or equal to three times/ week for over 1 year) individuals. $\mathrm{HR}_{\max }$ was inversely related to age in both males and females with no difference observed in $\mathrm{HR}_{\max }$ between genders or between sedentary (211-0.8×age), active (207-0.7×age) and endurancetrained $(206-0.7 \times$ age $)$ subjects. When pooled together, the researchers developed the regression equation 208$0.7 \times$ age for estimating $\mathrm{HR}_{\max }$ in healthy aging humans and showed that this equation produces significantly different age-predicted $\mathrm{HR}_{\max }$ from the traditional 220-age equation. Importantly, the latter equation significantly underestimates $\mathrm{HR}_{\max }$ and submaximal heart rate exercise intensities in older adults, particularly in the older age groups.

$\mathrm{HR}_{\max }$ has been shown to decrease in both males and females [47] at the same rate in both aging athletes and sedentary populations $[54,56,57,71,72,108]$ at approximately one beat per year after the age of 10 years. Hawkins et al. [47] examined longitudinal changes in $\mathrm{VO}_{2 \max }, \mathrm{HR}_{\max }$, and training volume in 86 male $(53.9 \pm$ 1.1 year) and 49 female ( $49.1 \pm 1.2$ year) masters endurance runners over an 8.5-year period. $\mathrm{VO}_{2 \max }$ and $\mathrm{HR}_{\max }$ declined significantly regardless of gender or age group.

In sedentary aging individuals, there is strong evidence to suggest that the decline in $\mathrm{VO}_{2 \max }$ with age is due in part to an age-related decline in $\mathrm{HR}_{\max }[71,77]$. Similarly, the observed age-related decrease in $\mathrm{HR}_{\max }$ has been suggested to be the major contributor to the age-related reduction in $\mathrm{VO}_{2 \max }$ in both male and female endurance athletes [48, 57, 71, 108]. Heath et al. [48] examined 16 highly trained masters endurance athletes ( $59 \pm 6$ year), 16 young trainingmatched athletes, and 18 untrained controls. $\mathrm{HR}_{\max }$ was $14 \%$ lower in the masters athletes than in the young athletes and $\mathrm{O}_{2}$ pulse during maximum exercise was identical in the two groups, suggesting that the major factor responsible for the lower $\mathrm{VO}_{2 \max }$ of the masters athletes is their lower $\mathrm{HR}_{\text {max }}$. In a later study, the same research team reported that the decline in $\mathrm{HR}_{\max }$ was solely responsible for differences in $\mathrm{VO}_{2 \max }$ between younger (25 years) and older (58 years) endurance athletes [40]. In a longitudinal 
study, over 25 years, Kasch et al. [53] investigated 12 physically active (walking, jogging, cycling, swimming) older men (44-79 years) who exercised an average 4.6 times per week for $66 \mathrm{~min}$ at $81 \%$ heart rate reserve. Over the 25 -year period, the investigators observed a significant age-related decline in both $\mathrm{HR}_{\max }(15 \mathrm{bpm})$ and stroke volume $(13 \mathrm{~mL})$.

An earlier study by Grimby et al. [39] observed that in a group of 51 year-old orienteers, the maximal cardiac output was $5 \mathrm{Lmin}^{-1}$, $17 \%$ lower than their 25 -year-old peers. While much of this difference was due to a decreased $\mathrm{HR}_{\text {max }}$, there was a small but nonsignificant decrease in values for maximal stroke volume. More recent data [76, 80] in older competitive runners supports this finding, although it remains arguable that at least part of the observed decrease in stroke volume of aging athletes may be due to a decreased training volume commonly observed in longitudinal studies of masters endurance athletes [42, 61, 71, 81, 100, 106, 108].

In summary, the available evidence from both crosssectional and longitudinal studies suggests that a decrease in $\mathrm{HR}_{\max }$ is the major contributor to the observed decreased $\mathrm{VO}_{2 \max }$ in masters endurance athletes, but that a decrease in maximal stroke volume may also contribute to the agerelated decline in $\mathrm{VO}_{2 \max }$.

\section{Maximum stroke volume}

The evidence for a reduction in maximal stroke volume in masters endurance athletes appears conclusive [70, 105]. Ogawa et al. [70] investigated the $\mathrm{VO}_{2}$, cardiac output and heart rate during both submaximal and maximal treadmill exercise in healthy younger and older sedentary and endurance-trained men and women. They observed a significant age-related decline in maximal stroke volume in both the endurance-trained men and women. In a later study, blood volume, $\mathrm{VO}_{2 \max }$, and exercise cardiac function were examined in 23 endurance-trained women (2063 years [105]). $\mathrm{VO}_{2 \max }$ declined progressively with age, and during maximal exercise, there was a decrease in both $\mathrm{HR}_{\max }$ and stroke volume with increasing age, suggesting that age-related decreases in these parameters contribute to the decreased $\mathrm{VO}_{2 \max }$ observed in masters endurance athletes.

Compared to age-matched sedentary controls, the available research suggests that maximal stroke volume of both male and female masters endurance athletes is elevated [43]. Hagmar et al. [43] used echocardiography and cycle ergometry exercise to establish that compared to agematched sedentary controls, postmenopausal former elite endurance athletes who are now recreational endurance athletes exhibit a significantly increased stroke volume $45 \pm 10$ vs $36 \pm 5 \mathrm{mLm}^{-2}$ ). Nottin et al. [69] assessed the effect of long-term endurance training on left ventricular (LV) relaxation in 14 male masters athletes with a history of intensive long-term endurance training using Doppler imaging. Stroke volume was significantly higher and submaximal exercise heart rate lower in masters athletes compared with aged-matched sedentary subjects. Taken together, these results suggest that long-term physical training maintains a high level of cardiac function and stroke volume in masters endurance athletes.

The most likely explanation for this enhanced cardiac function is the morphological adaptations that chronic endurance training stimulates in cardiac muscle [29]. In masters endurance athletes, relatively few studies with small subject numbers have examined cardiac structure and function after long-term endurance training [26, 36, 43, $49,82]$. Similar to the adaptations to endurance training observed in younger athletes (29), these cross-sectional and longitudinal studies have shown that endurance training in male and female masters athletes leads to increased cardiac dimensions [36, 43, 82], increased posterior wall thickness and interventricular septum thickness [36], increased left and right ventricular mass $[26,36,49]$.

\section{Blood volume}

An expansion of blood volume is a common finding after endurance training [21-23]. A 20-25\% expansion of blood volume that accompanies endurance training provides advantages of greater body fluid to facilitate enhanced thermoregulatory ability through sweating, a larger vascular volume for greater cardiac filling and stroke volume and, thus, enhanced cardiovascular stability during both exercise and changes in posture [22].

The majority of cross-sectional studies examining the effect of aging on blood volume have consistently observed a decrease in blood volume in normal populations [23, 25]. However, when the correlation between blood volume and age was partialed for $\mathrm{VO}_{2 \max }$, the relationship was a moderately positive partial correlation of $r=0.39$ [23], suggesting that the age-related decrease in $\mathrm{VO}_{2 \max }$ rather than aging per se may explain the decrease in blood volume observed with age in normal sedentary populations.

In support of this suggestion, high correlations have been observed between $\mathrm{VO}_{2 \max }$ and blood volume in both young [21] and older male [41] and female [89] endurance athletes or aging individuals with high $\mathrm{VO}_{2 \max }$ values [23] In their classic study, Hagberg et al. [41] demonstrated that compared to age-matched sedentary men, older endurance athletes exhibited significantly higher $\mathrm{VO}_{2 \max }$ values, significantly larger peak exercise stroke volume indexes (75 vs $57 \mathrm{mLm}^{-2}$ ), 17\% larger end-diastolic volume indexes, and significantly larger relative plasma (46 vs $\left.38 \mathrm{mLkg}^{-1}\right)$, red cell (30 vs $26 \mathrm{mLkg}^{-1}$ ), and total blood 
volumes (76 vs $64 \mathrm{mLkg}^{-1}$ ). In the total group, $\mathrm{VO}_{2 \max }$ significantly correlated with plasma, red cell, and total blood volumes. Maximal stroke volume was correlated with the blood volume variables. Multiple regression analyses showed that blood volume was an independent determinant of both $\mathrm{VO}_{2 \max }$ and exercise stroke volume. These findings strongly suggest that expanded blood volumes contribute to the higher peak exercise left ventricular end-diastolic volume, stroke volume, and cardiac output and $\mathrm{VO}_{2 \max }$ in masters endurance athletes by eliciting both chronic volume overload and increased utilization of the Frank-Starling effect during exercise.

Thus, the available cross-sectional studies suggest that individuals who undertake regular endurance training exhibit significantly larger blood volumes than sedentary individuals of the same age. Moreover, it appears that this finding is consistent across both males and females and is independent of age.

In summary, numerous studies have observed a significant inverse relationship between $\mathrm{VO}_{2 \max }$ and age in highly trained male and female endurance athletes. The decreased $\mathrm{VO}_{2 \max }$ appears related to age-related decreases in $\mathrm{HR}_{\max }$ rather than significant changes in stroke volume, cardiac morphology or blood volume. However, the agerelated declines in endurance performance appear slightly smaller than the age-related decline in $\mathrm{VO}_{2 \max }$ (94). This would suggest that there may be declines in other major factors influencing endurance performance such as lactate threshold or exercise economy.

\section{Lactate threshold}

Coyle [24] identified that lactate threshold is a major determining factor in endurance performance. Lactate threshold is defined as the exercise intensity (velocity or $\left.\% \mathrm{VO}_{2 \max }\right)$ at which blood lactate increases significantly above baseline level. Research has consistently shown that both $\mathrm{VO}_{2}$ at lactate threshold [31] and velocity at lactate threshold are better predictors of endurance running performance than $\mathrm{VO}_{2 \max }[6,68]$ in younger distance runners. In older runners, it appears that endurance running performance is correlated with both $\mathrm{VO}_{2 \max }$ and velocity at lactate threshold in male runners $[50,96]$ and highly trained older female runners [28, 108]. The latter study used stepwise regression analyses on subjects pooled from different age groups and determined that the majority $(60 \%)$ of the variability in performance for runners aged 23-47 year was explained by the running velocity at which LT occurred, whereas $\mathrm{VO}_{2 \max }$ explained the majority (74\%) of the variability for the runners aged 37-56 years. They concluded that both decreases in $\mathrm{VO}_{2 \max }$ and running velocity at LT were the two physiological phenomena most closely associated with age-related declines in $10-\mathrm{km}$ run performance in highly trained female runners. However, the contributions of these two mechanisms to the declines in endurance performance appear not to be uniform with advancing age.

When expressed as a percentage of $\mathrm{VO}_{2 \max }$, lactate threshold does not appear to decrease significantly with age in either male $[2,107]$ or female $[28,108]$ distance runners. Allen et al. [2] observed that male masters runners $(56 \pm$ 5 year) had a significantly $(9 \%)$ lower $\mathrm{VO}_{2 \max }$ than young runners ( $25 \pm 3$ year), despite being matched for $10-\mathrm{km}$ run performance. While running economy was not significantly different between the groups, the masters runners attained a 2.5-mmolL ${ }^{-1}$ blood lactate level during steady-state exercise at a higher percentage of their $\mathrm{VO}_{2 \max }(92 \mathrm{vs} 89 \%$ ), although both groups attained this lactate level at the same running speed and $\mathrm{VO}_{2}$. Similarly, the later longitudinal study by Wiswell et al. [107] observed that lactate threshold as $\% \mathrm{VO}_{2 \max }$ did not differ between male and female endurance runners and increased significantly with age in both groups. In a heterogeneous population of aging endurance athletes, it is the exception to the rule to have older athletes performing and younger athletes in any given event. Thus, when older and younger endurance athletes are not matched for performance, endurance performance velocity decreases with age $[5-9,27,39,35,51,92,94$, 109] suggesting that the physiological steady-state during endurance performance may be influenced by age.

While the research examining lactate threshold in masters athletes suggests aging may improve or have minimal effect on lactate threshold as a percentage of $\mathrm{VO}_{2 \max }[5,6,107]$, more recent research has examined the maximal lactate steady state in masters athletes [63]. Maximal lactate steady state is defined as the highest concentration of blood lactate that can be maintained $\left( \pm 1 \mathrm{mmolL}^{-1}\right)$ during the last $20 \mathrm{~min}$ of a 30 -min constant workload test. Mattern et al. [63] determined $\mathrm{VO}_{2 \max }$ and maximal lactate steady state in three age groups: young ( $25.9 \pm 1.0$ year), middle-aged ( $43.2 \pm 1.0$ year), and older (64.6 \pm 2.7 year) of male competitive cyclists and triathletes matched for training intensity and duration. The researchers observed significant differences in $\mathrm{VO}_{2 \max }$ among all age groups: $67.7 \pm 1.2 \mathrm{mLkg}^{-1} \mathrm{~min}^{-1}, 56.0 \pm 2.6 \mathrm{mLkg}^{-1} \mathrm{~min}^{-1}$, $47.0 \pm 2.6 \mathrm{mLkg}^{-1} \mathrm{~min}^{-1}$ in the young, middle-aged and older athletes, respectively. When expressed as a percentage of $\mathrm{VO}_{2 \max }$, there was also a significant age-related decrease in the relative maximal lactate steady-state exercise intensity: $80.8 \pm 0.9 \%, 76.1 \pm 1.4 \%, 69.9 \pm 1.5 \%$ in the young, middle-aged, and older athletes, respectively. Thus, it would appear that when masters endurance athletes are not matched for performance, both the velocity at race pace and lactate steady state decline with age.

The above studies examining the effect of age on maximal lactate steady state or lactate threshold have used 
cross-sectional study designs. Marcell et al. [61] used both a cross-sectional and longitudinal study design to explore the relationship between lactate threshold and running performance in male $(n=51)$ and female $(n=23)$ masters endurance runners aged 39 to 77 years over a period of $5.8 \pm 1.6$ years. They observed a significant decrease in both $\mathrm{VO}_{2 \max }$ and training volume irrespective of age and gender and an increase in lactate threshold as a percent of $\mathrm{VO}_{2 \max }$ with age. Crucially, the changes in lactate threshold were not related to changes in fitness or performance and were very unstable over time. They concluded that the lactate threshold may be less precise than $\mathrm{VO}_{2 \max }$ or performance in the prescription of exercise intensities in older endurance athletes, supporting the earlier suggestion of Wiswell et al. [107] who also observed age-related increases in lactate threshold as a percent of $\mathrm{VO}_{2 \max }$ in male and female endurance runners.

In summary, the available data suggests that when expressed as a performance velocity, there is an age-related reduction in lactate threshold and maximal lactate steady state that contributes to a reduction in endurance performance in masters athletes. However, when expressed as a percentage of $\mathrm{VO}_{2 \max }$, lactate threshold increases in masters endurance athletes, suggesting this decrease in lactate threshold exercise intensity with age may be secondary to age-related decreases in $\mathrm{VO}_{2 \max }$.

\section{Economy}

In modeling endurance performance, Coyle [24] identified that economy is a major determining factor in endurance performance. Economy is defined as the oxygen cost to exercise at a given exercise intensity (velocity or $\% \mathrm{VO}_{2 \max }$ ) and has been shown to be a stronger predictor of endurance performance than $\mathrm{VO}_{2 \max }$ in a homogenous group of endurance athletes $[2,19]$.

A few studies have examined economy in masters endurance athletes $[2,28]$. In a study of male $10-\mathrm{km}$ runners matched for run performance, running economy was similar in both young $(25 \pm 3$ year) and older $(56 \pm$ 5 year) runners [2]. Similarly, Evans et al. [28] tested the hypothesis that declines in $10-\mathrm{km}$ run performance in females was associated with decreases in $\mathrm{VO}_{2 \max }$, lactate threshold, and running economy. In 31 highly trained female runners aged 23-56 years, they observed that both $10-\mathrm{km}$ performance and age were significantly correlated with $\mathrm{VO}_{2 \max }$ and running velocity and $\mathrm{VO}_{2}$ at lactate threshold. However, both $10-\mathrm{km}$ performance and age were not correlated with running economy in the highly trained and competitive female endurance runners [28].

In summary, exercise economy appears to not appear to change with age in masters endurance athletes suggesting that economy does not contribute significantly to agerelated decreases in endurance performance commonly observed in masters athletes.

\section{Muscle mass}

A decreased muscle mass has been suggested as a contributor to the age-related decline in $\mathrm{VO}_{2 \max }$ in sedentary aging individuals $[15,33]$. Fleg and Lakatta [33] measured 24-h urinary creatinine excretion, (an index of muscle mass) in 184 healthy volunteers aged $22-87$ years from the Baltimore Longitudinal Study of Aging. They observed a significant positive correlation between $\mathrm{VO}_{2 \max }$ and creatinine excretion in both men and women. $\mathrm{VO}_{2 \max }$ showed a strong negative linear relationship with age in both men and women. When $\mathrm{VO}_{2 \max }$ was normalized for creatinine excretion, the variance in the $\mathrm{VO}_{2 \max }$ decline attributable to age declined from 60 to $14 \%$ in men and from 50 to $8 \%$ in women, suggesting that muscle mass may influence the age-related decline in $\mathrm{VO}_{2 \max }$ observed with age in healthy adults.

Muscle atrophy may also play a role in the observed agerelated decrease in $\mathrm{VO}_{2 \max }$ in masters endurance athletes [47, 73]. Early studies examining declines in endurance performance and $\mathrm{VO}_{2 \max }$ in masters endurance athletes measured lean body mass and observed age-related declines in $\mathrm{VO}_{2 \max }$ relative to both total body weight or lean body mass [33, 48, $70]$. While these early studies observe age-related declines in $\mathrm{VO}_{2 \max }$ relative to lean body mass in masters endurance athletes, they did not statistically adjust their data for age or gender differences in body composition, a consistent agerelated finding in masters endurance athletes $[47,72,101]$.

In the first study to examine the effect of decreases in muscle mass on $\mathrm{VO}_{2 \max }$ in older athletes, Proctor and Joyner [73] observed that approximately $50 \%$ of the difference in whole body lean body mass could be explained by reduced appendicular muscle mass in older vs younger endurance athletes. Moreover, they observed that approximately $14 \%$ of the age difference in $\mathrm{VO}_{2 \max }$ relative to appendicular muscle mass could be explained by this age-related difference. Hawkins et al. [47] later examined longitudinal changes in $\mathrm{VO}_{2 \max }, \mathrm{HR}_{\max }$, and training volume in 86 male (53.9 \pm 1.1 year) and 49 female $(49.1 \pm 1.2$ year) masters endurance runners over 8.5 years. $\mathrm{VO}_{2 \max }$ and $\mathrm{HR}_{\max }$ declined significantly regardless of gender or age. Men with the greatest loss in $\mathrm{VO}_{2 \max }$ had the greatest loss in lean body mass, suggesting that decreased muscle mass may have contributed to the age-related reduction in $\mathrm{VO}_{2 \max }$. However, studies such as the one by Hawkins et al. [47] that have suggested age-related decreases in $\mathrm{VO}_{2 \max }$ in masters endurance athletes are due to decreases in lean body mass are difficult to interpret due 
to the confounding effects of age-related changes in body fat and muscle oxidative capacity $[15,33]$.

One of the most commonly observed declines with aging is a decrease in muscle mass $[13,28]$. While several crosssectional studies of strength- or power-trained masters athletes observed greater muscle mass compared to sedentary age-matched controls [58, 86], it appears that chronic endurance training into older age does not maintain overall muscle mass $[44,58,85]$. These studies showed that masters endurance athletes had similar muscle mass as age-matched sedentary controls and reduced muscle mass compared to younger sedentary or young endurance-trained individuals.

Recent studies have been able to measure appendicular muscle mass in aging sedentary and endurance trained individuals using dual-energy X-ray absorptiometry [13, 91]. Sugawara et al. [91] studied 131 healthy men aged 2079 years who were either sedentary or endurance-trained. Appendicular (arms and legs) muscle mass in the endurance-trained middle-aged and older men was significantly higher than their sedentary peers. However, the rate of decline in appendicular muscle mass with age $\left(1.3 \mathrm{gkg}^{-1}\right.$ BWyear $^{-1}$ ) was similar between the two groups. The same investigators observed a positive correlation $(p<0.01)$ between $\mathrm{VO}_{2 \max }$ and appendicular muscle mass relative to total body mass, suggesting that the age-related decrease in appendicular muscle mass contributes to the age-related decrease in $\mathrm{VO}_{2 \max }$ in masters endurance athletes.

While active muscle mass may decrease in size in masters endurance athletes, a number of studies have suggested better muscle structure and architecture in older endurance-trained individuals compared to age-matched sedentary controls $[58,85,86]$. In an investigation of the quadriceps size in male [85] and female [86] endurance athletes who had a lifelong training history in competitive sports, the athletes exhibited firmer fasciae and connective tissue septa but less fat and connective tissue infiltration than age-matched sedentary controls.

In summary, it would appear that endurance training into older age may not reduce the age-related loss of muscle mass observed in a sedentary aging population, but the quantity and quality of muscle may be enhanced through maintenance of contractile tissue. Moreover, it appears that the age-related decrease in lean body mass and appendicular muscle mass in particular, contributes to the age-related decrease in $\mathrm{VO}_{2 \max }$ and thus endurance performance in masters athletes.

\section{Peripheral factors affecting maximal aerobic power}

The modified Fick equation suggests that $\mathrm{VO}_{2 \max }$ is the product of both central factors as well as maximal arteriovenous oxygen difference (peripheral factors [4]). A common observation in studies of masters endurance athletes is that there is an age-related decrease in arteriovenous oxygen difference [76, 94]. However, it appears that when young and older endurance athletes are matched for training volume, this age-related decrease is attenuated or disappears [34, 40], suggesting that the well-observed decrease in training volume and intensity with age in masters endurance athletes $[54,56,100,101]$ may explain the decline in arteriovenous oxygen difference.

To explain this age-related decline in arteriovenous oxygen difference, the peripheral factors identified by Coyle [24] as influencing endurance performance will be discussed. These include muscle fiber composition and size, muscle capillarization, and aerobic enzyme activity.

Fiber composition, morphology, and capillarization

Normal aging is strongly characterized by muscular atrophy due to a decrease in both size and number of muscle fibers, especially of the type II fibers [12, 60]. In aging endurance athletes, there also appears to be a maintenance or increase in the percentage of type I muscle fibers $[16,58,100]$, typical of that seen in sedentary aging individuals [3]. In support of an increased type I fiber composition in aging endurance athletes, Coggan [16] demonstrated that a group of aged ( $>60$ year) endurance-trained runners possessed a similar fiber composition ( $>60 \%$ type I fibers) to a group of younger performance- and training-matched runners. However, the older runners possessed 34\% larger type I fibers than the younger cohort and $25 \%$ larger than younger competitive runners. Interestingly, the younger competitive runners demonstrated muscle fiber composition significantly different ( $>70 \%$ type I fibers) than the older runners. Both younger groups possessed a significantly higher type II-to-type I fiber ratio, supporting the atrophy or crossexpression of the type II fibers [16].

As with aging sedentary individuals (12), a common observation of aging endurance athletes is a decreased cross-sectional area of type II fibers while maintaining or increasing the size of their type I fibers as a result of a shift towards a higher expression of myosin heavy chain (MHC) isoforms of type I fibers $[1,44,58,74,101]$. In their 22year longitudinal study of former elite masters endurance runners who maintained high intensity endurance training, Trappe et al. [101] observed a 7\% decrease in type I and IIa fiber area compared to age-matched sedentary controls. This decrease lead to the type I and IIa being $15 \%$ weaker in the runners that, when corrected for the decrease in fiber size, was no different to the sedentary controls. Using single fiber preparations, the researchers observed that the contractile velocity of the type I fibers only was $18 \%$ faster than the sedentary controls. However, despite the greater contractile velocity, the contractile power of the endurance 
runners was $13 \%$ (type I) and 27\% (type IIa) less powerful than the single fibers of the age-matched sedentary controls. These data strongly suggest that the muscle fibers of masters endurance runners are smaller, weaker, and less powerful than normal sedentary individuals.

This most likely reflects the adaptations that are beneficial for endurance performance within the muscle such as decreased diffusion distances for oxygen and substrates during endurance performance and may help to attenuate decreases in endurance performance despite decreases in $\mathrm{VO}_{2 \max }[100]$. However, the longitudinal changes within the muscle most likely reflect the continued training habits of masters endurance athletes $[1,16,44,74,100,102]$.

The observed type I fiber hypertrophy in the masters runners has previously been observed in elite younger runners who trained for long duration and at high intensity [37]. In support of this suggestion, Coggan et al. [16] observed a correlation $(r=0.62 ; P<0.001)$ between duration of training and type I fiber area in well-trained masters runners. Similarly, a longitudinal study by Trappe [100] demonstrated that a highly-trained group of endurance athletes with a high composition of type I fibers (>70\%) showed no significant change in type I fiber area across 20 years of continued endurance running training. However, this increased reliance on type I fiber may detract from the power output at performance velocity by lowering the speed of contraction of the working muscle tissue [101].

The increased type I fiber composition and reduced size of type II fiber size of masters endurance athletes may have a positive impact on muscle capillarization and oxidative metabolism and thus endurance performance [16, 20, 38]. Coggan et al. [16] observed greater capillary-to-fiber ratios and capillary contacts per fiber in masters endurance runners compared with training- and performance-matched younger runners. Furthermore, a longitudinal study of 33 aged (42-72 year) male endurance runners over an 18-year period noted that the still active older athletes had a higher degree of capillarization compared to young and old sedentary controls [38]. This supports more recent finding that capillarization is maintained within muscles which are subject to continued activity [16].

Therefore, it appears that capillary density and capillaryfiber ratio are maintained in athletes who continue endurance training into older age. This maintenance of muscle capillarization most likely reflects the increase in type I fiber composition observed in masters endurance athletes. As a result, this may have a positive effect on aerobic enzyme activities and muscle oxidative capacity.

Aerobic enzyme activity levels

Previous studies have suggested muscle oxidative capacity decreases with age in sedentary individuals $[79,98]$. This decrease may be due to a decrease in aerobic enzyme (i.e. citrate synthase (CS), succinate dehydrogenase (SDH), 2oxogluterate-dehydrogenase (2-OGDH), $\beta$-hydroxy-CoA dehydrogenase ( $\beta$-HAD) activity $[16-18,74,98,101]$, increased mitochondrial uncoupling [10], or from the decreased delivery of $\mathrm{O}_{2}$ due to capillary atrophy [17].

Endurance training has a larger influence on oxidative capacity than aging [79]. In masters endurance athletes, contrasting evidence has been produced on changes in muscle oxidative characteristics $[18,100]$. Coggan et al. [18] demonstrated that older ( 60 -year) endurance-trained athletes exhibit significantly lower CS activity than a training-matched younger cohort. In contrast, a longitudinal study by Trappe et al. [100] observed that SDH activity was maintained over 20 years in highly trained endurance runners. They also reported that $\mathrm{CS}$ and SDH activities from the $v$. lateralis were dependent upon training activities as there were significant differences between highly trained, fitness-trained, and untrained older men studies. Similarly, Coggan et al. [18] reported that masters runners possessed significantly higher $\mathrm{SDH}$ and $\beta$-HAD activities than performance-matched younger runners. In addition, CS activity was significantly higher in this older group.

In summary, it appears that the oxidative enzyme activities of masters endurance athletes appear to be maintained or increased compared to performance-matched younger athletes. This may support the suggestion that an increased reliance on oxidative energy pathways is required with increasing age as a result of the histochemical changes observed with age (12).

\section{Conclusion}

In conclusion, the current research suggests that age-related reductions in endurance performance observed in masters athletes are primarily related to age-related decreases in $\mathrm{VO}_{2 \max }$ secondary to age-related decreases in $\mathrm{HR}_{\max }$, lactate threshold velocity, blood volumes, and muscle mass. However, the age-related declines in endurance performance and its physiological determinants appear to be mediated by a reduction in the intensity and volume of training commonly observed in masters endurance athletes.

\section{References}

1. Aagaard P, Magnusson PS, Larsson B, Kjaer M, Krustrup P (2007) Mechanical muscle function, morphology, and fiber type in lifelong trained elderly. Med Sci Sports Exerc 39:1989-1996

2. Allen WK, Seals DR, Hurley BF, Ehsani AA, Hagberg JM (1985) Lactate threshold and distance-running performance in young and older endurance athletes. J Appl Physiol 58:12811284 
3. Andersen JL, Terzis G, Kryger A (1999) Increase in the degree of co-expression of myosin heavy chain isoforms in skeletal muscle fibers of the very old. Muscle Nerve 22:449-454

4. Åstrand PO, Rodahl K, Dahl HA, Stromme S (2003) Textbook of work physiology: physiological bases of exercise, 4th ed. Human Kinetics, Chicago, Illinois

5. Baker AB, Tang YQ, Turner MJ (2003) Percentage decline in Masters superathlete track and field performance with aging. Exp Aging Res 29:47-65

6. Bassett DR, Howley ET (2000) Limiting factors for maximum oxygen uptake and determinants of endurance performance. Med Sci Sports Exerc 32:70-84

7. Bird S, Balmer J, Olds T, Davison RCR (2001) Differences between the sexes and age-related changes in orienteering speed. J Sports Sci 19:243-252

8. Bird SR, Theakston SC, Owen A, Nevill AM (2003) Characteristics associated with $10-\mathrm{km}$ running performance among a group of highly trained male endurance runners aged 21-63 years. J Aging Phys Act 11:333-350

9. Bongard V, McDermott AY, Dallal GE, Schaefer EJ (2007) Effect of age and gender on physical performance. Age 29:77-85

10. Brierley EJ, Johnson MA, James OF, Turnbull DM (1997) Mitochondrial involvement in the ageing process. Facts and controversies. Mol Cell Biochem 174:325-328

11. Brown SJ, Ryan HJ, Brown JA (2007) Age-associated changes in $\mathrm{VO}_{2}$ and power output - a cross-sectional study of endurance trained New Zealand cyclists. J Sport Sci Med 6:477-483

12. Brunner F, Schmid A, Sheikhzadeh A, Nordin M, Yoon J, Frankel V (2007) Effects of aging on Type II muscle fibers: a systematic review of the literature. J Aging Phys Act 15:336-348

13. Bunout D, de la Maza MP, Barrera G, Leiva L, Gattas V, Hirsch S (2007) Assessment of sarcopenia: longitudinal versus cross sectional body composition data. Aging Clin Exp Res 19:295299

14. Burgomaster KA, Howarth KR, Phillips SM, Rakobowchuk M, Macdonald MJ, McGee SL, Gibala MJ (2007) Similar metabolic adaptations during exercise after low volume sprint interval and traditional endurance training in humans. J Physiol (Lond) 586:151-160

15. Buskirk ER, Hodgson JL (1987) Age and aerobic power: the rate of change in men and women. Fed Proc 46:1824-1829

16. Coggan AR, Spina RJ, Rogers MA, King DS, Brown M, Nemeth PM, Holloszy JO (1990) Histochemical and enzymatic characteristics of skeletal muscle in master athletes. J Appl Physiol 68:1896-1901

17. Coggan AR, Spina RJ, King DS, Rogers MA, Brown M, Nemeth PM, Holloszy JO (1992) Histochemical and enzymatic comparison of the gastrocnemius muscle of young and elderly men and women. J Gerontol Biol Sci 47:B71-B76

18. Coggan AR, Abduljalil AM, Swanson SC, Earle MS, Farris JW, Mendenhall LA, Robitaille PM (1993) Muscle metabolism during exercise in young and older untrained and endurancetrained men. J Appl Physiol 75:2125-2133

19. Conley DL, Krahenbuhl GS (1980) Running economy and distance running performance of highly trained athletes. Med Sci Sports Exerc 12:357-360

20. Conley KE, Esselman PC, Jubrias SA, Cress ME, Inglin B, Mogadam C, Schoene RB (2000) Ageing, muscle properties and maximal $\mathrm{O}_{2}$ uptake rate in humans. J Physiol (Lond) 526:211-217

21. Convertino VA (1991) Blood volume: its adaptation to endurance training. Med Sci Sports Exerc 23:1338-1348

22. Convertino VA (2007) Blood volume response to physical activity and inactivity. Am J Med Sci 334:72-79

23. Convertino VA, Ludwig DA (2000) Validity of $\mathrm{VO}_{2 \max }$ in predicting blood volume: Implications for the effect of fitness on aging. Am J Physiol: Reg, Integ Comp Physiol 279:R1068-1075
24. Coyle EF (1995) Integration of the physiological factors determining endurance performance ability. Exerc Sports Sci Rev 23:25-63

25. Davy KP, Seals DR (1994) Total blood volume in healthy young and older men. J Appl Physiol 76:2059-1062

26. Di Bello V, Lattanzi F, Picano E, Talarico L, Caputo MT, Di Muro C, Santoro G, Lunardi M, Distante A, Giusti C (1993) Left ventricular performance and ultrasonic myocardial quantitative reflectivity in endurance senior athletes: an echocardiographic study. Eur Heart J 14:358-363

27. Donato AJ, Tench K, Glueck DH, Seals DR, Eskurza I, Tanaka H (2003) Declines in physiological functional capacity with age: a longitudinal study in peak swimming performance. J Appl Physiol 94:764-769

28. Evans SL, Davy KP, Stevenson ET, Seals DR (1995) Physiological determinants of $10-\mathrm{km}$ performance in highly trained female runners of different ages. J Appl Physiol 78:1931-1941

29. Fagard RH (1996) Athlete's heart: a meta-analysis of the echocardiographic experience. Int J Sports Med 17:S140-S144

30. Fairbrother JT (2007) Prediction of 1500-m freestyle swimming times for older masters all-American swimmers. Exp Aging Res $33: 461-471$

31. Fay L, Londeree BR, LaFontaine TP, Volek MR (1989) Physiological parameters related to distance running performance in female athletes. Med Sci Sports Exerc 21:319-324

32. Fitzgerald MD, Tanaka H, Tran ZV, Seals DR (1997) Agerelated declines in maximal aerobic capacity in regularly exercising versus sedentary women: a meta-analysis. J Appl Physiol 83:160-165

33. Fleg JL, Lakatta EG (1988) Role of muscle loss in the ageassociated reduction in $\mathrm{VO}_{2 \max }$. J Appl Physiol 65:1147-1151

34. Fuchi T, Iwaoka K, Higuchi M, Kobayashi S (1989) Cardiovascular changes associated with decreased aerobic capacity and aging in long-distance runners. Eur J Appl Physiol 58:884-889

35. Fung L, Ha A (1994) Changes in track and field performance with chronological aging. Int J Aging Hum Dev 38:171-180

36. Giada F, Bertaglia E, De Piccoli B, Franceschi M, Sartori F, Raviele A, Pascotto P (1998) Cardiovascular adaptations to endurance training and detraining in young and older athletes. Int J Cardiol 65:149-155

37. Gollnick PD, Saltin B (1982) Significance of skeletal muscle oxidative enzyme enhancement with endurance training. Clin Physiol 2:1-12

38. Grimby G, Saltin B (1983) The ageing muscle. Clin Physiol 3:209-218

39. Grimby G, Nilsson NJ, Saltin B (1966) Cardiac output during submaximal and maximal exercise in active middle-aged athletes. J Appl Physiol 21:1150-1156

40. Hagberg JM, Allen WK, Seals DR, Hurley BF, Ehsani AA, Holloszy JO (1985) A hemodynamic comparison of young and older endurance athletes during exercise. J Appl Physiol 58:2041-2046

41. Hagberg JM, Goldberg AP, Lakatta L, O'Connor FC, Becker LC, Lakatta EG, Fleg JL (1998) Expanded blood volumes contribute to the increased cardiovascular performance of endurance-trained older men. J Appl Physiol 85:484-489

42. Hagerman FC, Fielding RA, Fiatarone MA, Gault JA, Kirkendall DT, Ragg KE, Evans WJ (1996) A 20-yr longitudinal study of Olympic oarsmen. Med Sci Sports Exerc 28:1150-1156

43. Hagmar M, Hirschberg AL, Lindholm C, Schenck-Gustafsson K, Eriksson MJ (2005) Athlete's heart in postmenopausal former elite endurance female athletes. Clin Journal Sport Med 15:257262

44. Harridge S, Magnusson G, Saltin B (1997) Life-long endurancetrained elderly men have high aerobic power, but have similar muscle strength to non-active elderly men. Aging (Milano) 9:80-87 
45. Hartley AA, Hartley JT (1986) Age differences and changes in sprint swimming performances of masters athletes. Exp Aging Res 12:65-70

46. Hastings DW, Kurth SB, Schloder M, Cyr D (1995) Reasons for participating in a serious leisure career: comparison of Canadian and US masters swimmers. Int Rev Sociol Sport 30:101-117

47. Hawkins SA, Marcell TJ, Victoria Jaque S, Wiswell RA (2001) A longitudinal assessment of change in $\mathrm{VO}_{2 \max }$ and maximal heart rate in masters athletes. Med Sci Sports Exerc $33: 1744-1750$

48. Heath GW, Hagberg JM, Ehsani AA, Holloszy JO (1981) A physiological comparison of younger and older endurance athletes. J Appl Physiol 51:634-640

49. Hood S, Northcote RJ (1999) Cardiac assessment of veteran endurance athletes: a 12 year follow up study. Br J Sports Med 33:239-243

50. Iwaoka K, Fuchi T, Higuchi M, Kobayashi S (1988) Blood lactate accumulation during exercise in older endurance runners. Int J Sports Med 9:253-256

51. Jokl P, Sethi PM, Cooper AJ (2004) Master's performance in the New York City Marathon 1983-1999. Br J Sports Med 38:408-412

52. Joyner MJ (1993) Physiological limiting factors and distance running: influence of gender and age on record performances. Exerc Sports Sci Revi 21:103-133

53. Kasch FW, Boyer JL, Van Camp SP, Verity LS, Wallace JP (1993) Effect of exercise on cardiovascular ageing. Age Ageing 22:5-10

54. Kasch FW, Boyer JL, Van Camp S, Nettl F, Verity LS, Wallace JP (1995) Cardiovascular changes with age and exercise. A 28-year longitudinal study. Scand J Med Sci Sports 5:147-151

55. Kasch FW, Boyer JL, Schmidt PK, Wells RH, Wallace JP, Verity LS, Guy H, Schneider D (1999) Ageing of the cardiovascular system during 33 years of aerobic exercise. Age Ageing 28:531536

56. Katzel LI, Sorkin JD, Fleg JL (2001) A comparison of longitudinal changes in aerobic fitness in older endurance athletes and sedentary men. J Am Geriatr Soc 49:1657

57. Kavanagh T, Shephard RJ (1990) Can regular sports participation slow the aging process? Data on masters athletes. Phys Sportsmed 18:94-104

58. Klitgaard H, Mantoni M, Schiaffino S, Ausoni S, Gorza L, Laurent-Winter C, Schnohr P, Saltin B (1990) Function, morphology and protein expression of ageing skeletal muscle: a cross-sectional study of elderly men with different training backgrounds. Acta Physiol Scand 140:41-54

59. Kolt GS, Driver RP, Giles LC (2004) Why older Australians participate in exercise and sport? J Aging Phys Act 11:185-198

60. Lexell J (1995) Human aging, muscle mass, and fiber type composition. J Gerontol: Biol Sci 2:253-265

61. Marcell TJ, Hawkins SA, Tarpenning KM, Hyslop DM, Wiswell RA (2003) Longitudinal analysis of lactate threshold in male and female master athletes. Med Sci Sports Exerc 35:810-817

62. Maron BJ, Araújo CG, Thompson PD et al (2001) Recommendations for preparticipation screening and the assessment of cardiovascular disease in masters athletes. Circulation 103:327-334

63. Mattern CO, Gutilla MJ, Bright DL, Kirby TE, Hinchcliff KW, Devor ST (2003) Maximal lactate steady state declines during the aging process. J Appl Physiol 95:2576-2582

64. Medic N, Starkes JL, Young BW (2007) Examining relative age effects on performance achievement and participation rates in masters athletes. J Sports Sci 25(12):1377-1384

65. Moore DH (1975) A study of group track and field records to relate age and running speed. Nature 253:264-265

66. Morgan DW, Baldini FD, Martin PE, Kohrt WM (1989) Ten kilometer performance and predicted velocity at $\mathrm{VO}_{2 \max }$ among well-trained male runners. Med Sci Sports Exerc 21:78-83
67. Newton M, Fry MD (1998) Senior olympians' achievement goals and motivational responses. J Aging Phys Act 6:256-270

68. Nicholson RM, Sleivert GG (2001) Indices of lactate threshold and their relationship with $10-\mathrm{km}$ running velocity. Med Sci Sports Exerc 33:339-342

69. Nottin S, Nguyen LD, Terbah M, Obert P (2004) Long-term endurance training does not prevent the age-related decrease in left ventricular relaxation properties. Acta Physiol Scand 181:209-215

70. Ogawa T, Spina RJ, Martin WH 3rd, Kohrt WM, Schechtman KB, Holloszy JO, Ehsani AA (1992) Effects of aging, sex, and physical training on cardiovascular responses to exercise. Circulation 86:494-503

71. Pimentel AE, Gentile CL, Tanaka H, Seals DR, Gates PE (2003) Greater rate of decline in maximal aerobic capacity with age in endurance-trained than in sedentary men. J Appl Physiol 94:2406-2413

72. Pollock ML, Mengelkoch LJ, Graves JE, Lowenthal DT, Limacher MC, Foster C, Wilmore JH (1997) Twenty-year follow-up of aerobic power and body composition of older track athletes. J Appl Physiol 82:1508-1515

73. Proctor DN, Joyner MJ (1997) Skeletal muscle mass and the reduction of $\mathrm{VO}_{2 \max }$ in trained older subjects. J Appl Physiol 82:1411-1415

74. Proctor DN, Sinning WE, Walro JM, Sieck GC, Lemon PW (1995) Oxidative capacity of human muscle fibre types: effects of age and training status. J Appl Physiol 78:2033-2038

75. Rahe RH, Arthur RJ (1975) Swim performance decrement over middle life. Med Sci Sports 7:53-58

76. Rivera AM, Pels AE 3rd, Sady SP, Sady MA, Cullinane EM, Thompson PD (1989) Physiological factors associated with the lower maximal oxygen consumption of master runners. J Appl Physiol 66:949-954

77. Rodeheffer RJ, Gerstenblith G, Becker LC, Fleg JL, Weisfeldt ML, Lakatta EG (1984) Exercise cardiac output is maintained with advancing age in healthy human subjects: cardiac dilatation and increased stroke volume compensate for a diminished heart rate. Circulation 69:203-213

78. Rogers MA, Hagberg JM, Martin WH 3rd, Ehsani AA, Holloszy JO (1990) Decline in $\mathrm{VO}_{2 \max }$ with aging in masters athletes and sedentary men. J Appl Physiol 68:1833-1837

79. Russ DW, Kent-Braun JA (2004) Is skeletal muscle oxidative capacity decreased in old age? Sports Med 34:221-229

80. Saltin B (1986) Physiological adaptation to physical conditioning. Old problems revisited.. Acta Med Scand 711:11-24

81. Schroeder TE, Hawkins SA, Hyslop D, Vallejo AF, Jensky NE, Wiswell RA (2007) Longitudinal change in coronary heart disease risk factors in older runners. Age Ageing 36:57-62

82. Seals DR, Hagberg JM, Spina RJ, Rogers MA, Schechtman KB, Ehsani AA (1994) Enhanced left ventricular performance in endurance trained older men. Circulation 89:198-205

83. Seiler KS, Spirduso WW, Martin JC (1998) Gender differences in rowing performance and power with aging. Med Sci Sports Exerc 30:121-127

84. Shaw KL, Ostrow A (2005) Motivation and psychological skills in the senior athlete. Eur Rev Aging Phys Act 2:22-34

85. Sipila S, Suominen H (1991) Ultrasound imaging of the quadriceps muscle in elderly athletes and untrained men. Muscle Nerve 14:527-533

86. Sipila S, Suominen H (1993) Muscle ultrasonography and computed tomography in elderly trained and untrained women. Muscle Nerve 16:294-300

87. Starkes JL, Weir PL, Young BW (2003) Retaining expertise: What does it take for older athletes to continue to excel? In: Starkes JL, Ericsson KA (eds) Advances in research on sport expertise. Human Kinetics, Champaign IL, pp 251-272 
88. Starkes JL, Weir PL, Singh P, Hodges NJ, Kerr T (1999) Aging and the retention of sports expertise. Int J Sport Psych 30:283-301

89. Stevenson ET, Davy KP, Seals DR (1994) Maximal aerobic capacity and total blood volume in highly trained middle-aged and older female endurance athletes. J Appl Physiol 77:16911696

90. Stones MJ, Kozma A (1981) Adult age trends in athletic performances. Exp Aging Res 7:269-280

91. Sugawara J, Miyachi M, Moreau KL, Dinenno FA, DeSouza CA, Tanaka H (2002) Age-related reductions in appendicular skeletal muscle mass: association with habitual aerobic exercise status. Clin Physiol Funct Imaging 22:169-172

92. Tanaka H, Higuchi M (1998) Age, exercise, performance, and physiological functional capacities. Adv Exerc Sports Physiol 4:51-56

93. Tanaka H, Seals DR (1997) Age and gender interactions in physiological functional capacity: Insight from swimming performance. J Appl Physiol 82:846-851

94. Tanaka H, Seals DR (2003) Invited review: dynamic exercise performance in masters athletes: insight into the effects of primary human aging on physiological functional capacity. $\mathrm{J}$ Appl Physiol 95:2152-2162

95. Tanaka H, Monahan KD, Seals DR (2001) Age-predicted maximal heart rate revisited. J Am Coll Cardiol 37:153-156

96. Tanaka K, Takeshima N, Kato T, Niihata S, Ueda K (1990) Critical determinants of endurance performance in middle-aged and elderly endurance runners with heterogeneous training habits. Eur J Appl Physiol 59:443-449

97. Tantrum M, Hodge K (1993) Motives for participating in masters swimming. NZ J Health Phys Ed Rec 26:3-7

98. Taylor DJ, Kemp GJ, Thompson CH, Radda GK (1997) Ageing: effects on oxidative function of skeletal muscle in vivo. Mol Cell Biochem 174:321-324

99. Trappe S (2007) Marathon runners: how do they age? Sports Med 37:302-305
100. Trappe SW, Costill DL, Fink WJ, Pearson DR (1995) Skeletal muscle characteristics among distance runners: a 20 -yr follow-up study. J Appl Physiol 78:823-829

101. Trappe SW, Costill DL, Vukovich MD, Jones J, Melham T (1996) Aging among elite distance runners: A 22-yr longitudinal study. J Appl Physiol 80:285-290

102. Trappe T, Lindquist DM, Carrithers JA (2001) Muscle-specific atrophy of the quadriceps femoris with aging. J Appl Physiol 90:2070-2074

103. Weir PL, Kerr T, Hodges NJ, McKay SM, Starkes JL (2002) Masters swimmers: how are they different from younger elite swimmers? An examination of practice and performance patterns. J Aging Phys Act 10:41-63

104. Weiss EP, Spina RJ, Holloszy JO, Ehsani AA (2006) Gender differences in the decline in aerobic capacity and its physiological determinants during the later decades of life. J Appl Physiol 101:938-944

105. Wiebe CG, Gledhill N, Warburton DE, Jamnik VK, Ferguson S (1999) Exercise cardiac function in young through elderly endurance trained women. Clin J Sport Med 31:684-691

106. Wilson TM, Tanaka H (2000) Meta-analysis of the ageassociated decline in maximal aerobic capacity in men: relation to training status. Am J Physiol: Heart Circ Physiol 278:H829$\mathrm{H} 834$

107. Wiswell RA, Jaque SV, Marcell TJ, Hawkins SA, Tarpenning KM, Constantino N, Hyslop DM (2000) Maximal aerobic power, lactate threshold, and running performance in master athletes. Med Sci Sports Exerc 32:1165-1170

108. Wiswell RA, Hawkins SA, Jaque SV, Hyslop D, Constantino N, Tarpenning K, Marcell T, Schroeder ET (2001) Relationship between physiological loss, performance decrement, and age in master athletes. J Gerontol: Med Sci 56:M618-M626

109. Young BW, Starkes JL (2005) Career-span analyses of track performance: Longitudinal data present a more optimistic view of age-related performance decline. Exp Aging Res 31:69-90 